\title{
Investigation of IL-17F (rs763780) gene Polymorphisms in cases with Iraqi renal failure patients
}

\author{
Saja Mohammed Mohsen', Abbas Abood Farhan², Mohammed Abdul-Daim Saleh ${ }^{3}$ \\ ${ }^{1}$ Middle Technical University, Baquba Technical Institute, Baquba, Iraq, ${ }^{2}$ Department of Biology - College of \\ education for pure science-Diyala University-Diyala - Iraq, ${ }^{3}$ Department of Biotechnology - College of Science - \\ Diyala University- Diyala-Iraq
}

\begin{abstract}
Renal failure (RF) is common disease, it is decrease of kidney function, glomerular filtration rate (GFR) this use to estimate the kidney function reduction usually is less than $60 \mathrm{~mL} / \mathrm{min}$, depending on global Burden of Disease, and the disease is ninth cause of death in the world, According to the global Burden of Disease. Our study is investigated in the relationship between IL-17F (rs763780) genes polymorphic variants in renal failure patients in Iraq. This study was accompanied around Iraqi renal failure patients, the period from February to November 2018. This study included 70 patients from Abn-Sina Center for dialysis and kidney disease, and 30 healthy controls. Tetra-primer ARMS-PCR is rapid, effective and developed assay used our study for studying in genotyping polymorphism of IL-17F (rs763780) genes. Result of our report including the correlation between the genotypes of IL-17F (rs763780) and the incidence of renal failure, as the results show a non-marked difference between patients and controls when genotype $\mathrm{T} / \mathrm{T}(\mathrm{OR}=0.75)$. Also, no significant difference between patients and control when genotype $\mathrm{C} / \mathrm{C}(\mathrm{OR}=0.85)$, while the genotype $\mathrm{T} / \mathrm{C}$ $(\mathrm{OR}=2.23)$ show important difference between control and patients more than two times. In conclusion, IL-17F play an essential role as pro-inflammatory cytokine in renal failure patients and development disease.
\end{abstract}

Keyword: - renal failure patients, rs763780, ARMS-PCR and IL-17F gene.

\section{Introduction}

Kidney is important organ, its function is regulation of the blood composition and volume, filtration the urine by eliminating the metabolic wastes, secretion of the end metabolism products and maintenance the acid or balance in the body via regulate fluids and electrolytes (1). Renal failure (RF) is common disease, usually is defined as the decrease of kidney function, glomerular filtration rate (GFR) this use to estimate the kidney function reduction usually is less than $60 \mathrm{~mL} / \min (2)$.

Interleukins -17F (IL-17F) types of cytokine produced from Th 17 cells. act on Stimulate inflammation and causing organ injury, also act on enhancing produce of pro-inflammatory cytokines by resident cells, that lead to increase penetration of neutrophils to affected organ and induce inflammation and damage in this organ such as kidney $(3,4)$. All these interleukins are similar in structure protein, but have in the $\mathrm{N}$ termini large sequence divergence.
Both IL-17A and IL-17F genes are located on chromosome 6p12.3-q13, and each consists of three exons and two intron the transcribed occurs in opposite direction, cytokine genes resulting together during gene replication also use same regulatory elements. In human, about of $50 \%$ sequence identity between IL17A and IL17F, both of these types produce homodimer and heterodimer proteins (5). Cytokine production may be effected by cytokine gene Polymorphisms through effect this gene on transcription. Single nucleotide polymorphisms (SNPs), acts on induce susceptibility or resistance to any infection, also may be used to diagnose some factors that contribute to cancers or inflammatory disease because SNP occurs in regulatory regions for cytokine gene ${ }^{(6)}$. Tetra-primer amplification refractory mutation system PCR (T-ARMS-PCR), these methods is very important to detect (SNP) genotyping because have several features rapid, ease to perform, an inexpensive, and accurate method (7). 
This method is ARMS-PCR modification; four primers are used. Two inner primers were allele specific and lead to produce two bands are different in size (lower molecular weight), this band appears depend on wild or mutant allele is present. And two external or outer primers produce non-allelic was control band. And the location of mismatch is middle for the specific allele primers and use four primers in these methods (8). While in ARMS-PCR the location of mismatch in $3^{\prime}$ end for the specific allele primers and utilize five primers. T-ARMS-PCR assay represent successfully methods to detect SNPs and others genetic or biological markers that associated with different disease such as effect TNF- $\alpha$ gene polymorphism in chronic pancreatitis patients (9).

Aim of our study is to determining the association and relationship between IL-17A (rs2275913) genes and Iraqi renal failure patients .

\section{Material and Method}

This study was accompanied around Iraqi renal failure patients, the period from February to November 2018. This study included 70 patients from Abn-Sina Center for dialysis and kidney disease and 30 healthy controls.

\section{1-Collection of samples:-}

Study groups Samples were Collected $2 \mathrm{ml}$ from whole blood in EDTE tube until extraction human genome. And use to investigate about IL-17F (rs763780) genes in study groups.

\section{2-Genomic DNA Extraction:}

The DNA was extracted by use special kit (Geneaid, Korea) according to the company directions.

\section{3-T-ARMS-PCR and Primer Design:}

Batchprimer3 program was used for designing, several types of primers are used included generic primers (including SSR primers with SSR detection) and SNP genotyping primers (including allele-specific primers, single-base extension primers, and tetraprimers for tetra-primer ARMS PCR), furthermore, DNA sequencing primers ${ }^{(10)}$. Show table 1 . T-ARMSPCR Analysis occurs by using Accupower PCR Premix (Bioneer, Korea) whole volume of $20 \mu \mathrm{L}$ included DNA $(4 \mu \mathrm{L})$, outer primers $(1 \mu \mathrm{L})$, inner primer $(1 \mu \mathrm{L})$ and add D.W $(12 \mu \mathrm{L})$. PCR process is start at $(95)^{\circ} \mathrm{C}$ for five minutes, then the second step is start at $(95)^{\circ} \mathrm{C}$ for twenty second, then annealing is start for twenty sec , annealing was carried out at $72{ }^{\circ} \mathrm{C}$ for twenty seconds and finally the process is finished at $(72){ }^{\circ} \mathrm{C}$ for three minute. Then electrophoresis are used for emigration of all PCR products after stained it by ethidium bromide.

\section{Statistical Analysis}

Our study used SAS program for statistical Analysis for differentiates between in parameters wherever LSD test was trying to compassion between groups (11). Whereas odds ratios (OR) and $95 \%$ confidence intervals (95\% CI) were calculated using MedCalc for Windows, version $18.10^{(12)}$.

Table 1 the used primers used in ARMS-PCR technique

\begin{tabular}{|l|l|l|l|l|l|}
\hline \multirow{2}{*}{ SNP } & System & Primer & Allele & Tm & Amplicon \\
\hline \multirow{5}{*}{$\begin{array}{l}\text { Is763780 } \\
\text { IL17F }\end{array}$} & Forward inner primer & GAGTGGATATGCACCTCTTACTGCAAAC & C & 62 & 158 \\
\cline { 2 - 6 } & Reverse inner primer & CGTCACCCCTGTCATCCAACA & T & 62 & 106 \\
\cline { 2 - 6 } & Forward outer primer & AGACAGGACTTGTTGCAGAGCACTG & & 62 \\
\cline { 2 - 6 } & Reverse outer primer & ATGAATTCCGTTCCCATCCAGC & & 62 \\
\hline
\end{tabular}

*Tm Temperature of melting 


\section{Result}

The renal failure patients group consisted of 70 patients, 40 males (57\%) and 30 females (43\%), with a mean age of $49.5 \pm 5.91$ years. The healthy control group consisted of 30 subjects, with a mean age of 30.3 \pm 3.62 years.

In IL-17F (rs763780), the fragment lengths for the specific amplicons were as follows; $158 \mathrm{bp}$ for the $\mathrm{C}$ allele and $106 \mathrm{bp}$ for the $\mathrm{T}$ allele. The presence of two specific amplicons for an SNP indicates heterozygosity. In addition, non-indicative amplicons resulting from the common primer pairs are always present $(215 \mathrm{bp}$ for the two outer primers) show figure 1.

The IL-17F (rs763780) TC, CC and TT genotypes figure (1) were detected in $5(7 \%), 4(6 \%)$ and $61(87 \%)$ patients, and in $1(3 \%), 2(7 \%)$ and $27(90 \%)$ controls, respectively. Frequency of genotype TC, CC and TT significantly increase in the groups of patients compared with control.

The genotype TT recorded highly ratio in both groups patients and control (57-90\%) which made it the common genotype for this locus in Iraqi population. both homozygous genotype showed preventive fraction according odds ratio $(0.85,0.75)$, while TC genotype according odds ratio consider as etiological fraction. The analysis of the allele impact, including both genotypes that containing $\mathrm{C}$ allele showed no significant association in patient group comparing with control $(\mathrm{p}=$ 0.829). According OR, allele $C$ tend to be risky allele, while allele $\mathrm{T}$ tend to be a preventive allele (Table 2).

According to the sex the results in Table (3) the genotype TT showed as preventive fraction according odds ratio (0.34), while TC and CC genotype according odds ratio consider as etiological fraction $(3.22,2.35)$ respectively. Also according $\mathrm{OR}$, allele $\mathrm{C}$ tend to be risky allele, while allele $\mathrm{T}$ tend to be a preventive allele.

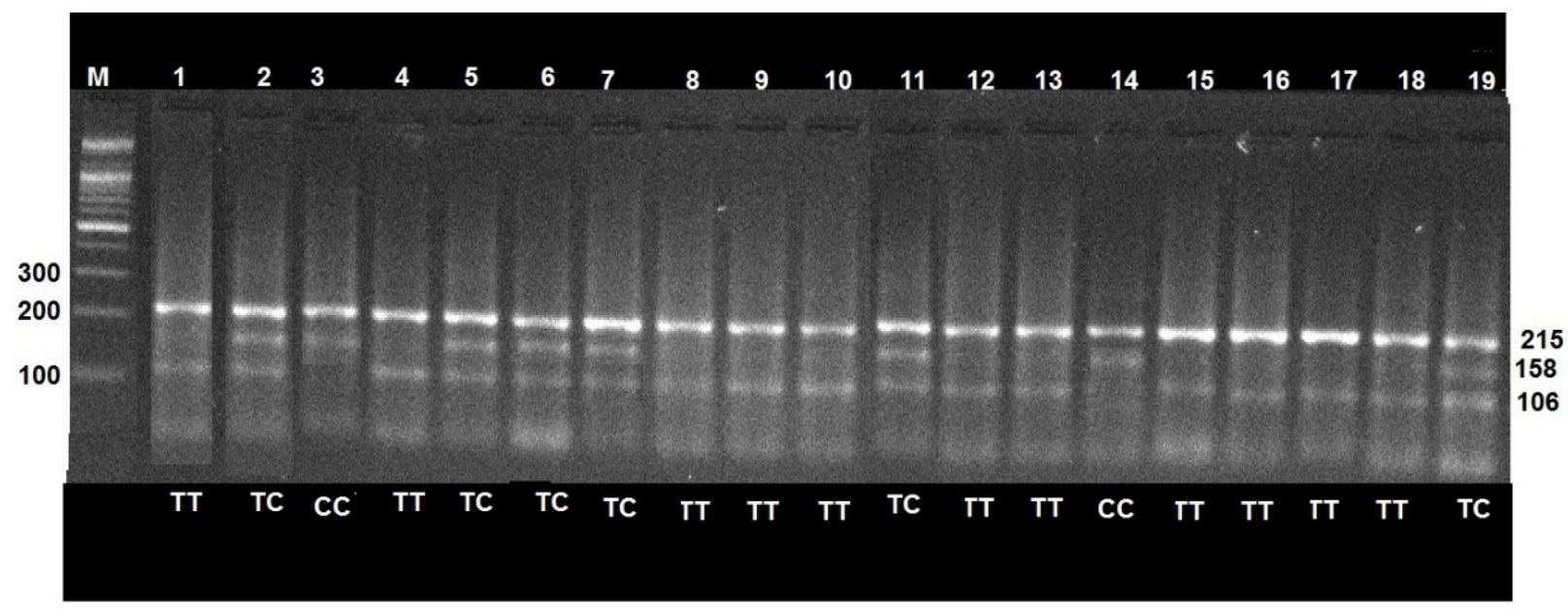

Figure (1): electrophoresis of samples on agarose gel by using T-ARMS-PCR assay: The IL-17F (rs763780) locus genotyping by T-ARMS-PCR resolved on a $2 \%$ agarose gel stained with ethidium bromide (45 min, 150V/cm, 1X Tris-acetic buffer). $215 \mathrm{bp}$, the bands are amplicon, and $\mathrm{T}$ and $\mathrm{C}$ allele-specific bands are $106 \mathrm{bp}$ and $158 \mathrm{bp}$ amplicons respectively (Bioneer, Korea). 
Table (2) Distribution of genotypes for the IL-17F (RS763780) gene samples of patients and healthy controls.

\begin{tabular}{|c|c|c|c|c|c|}
\hline SNP & Genotype & $\begin{array}{l}\text { Patients* } n=70 n \\
(\%)\end{array}$ & $\begin{array}{l}\text { Control } n=30 \\
N(\%)\end{array}$ & $\mathrm{OR}(95 \% \mathrm{CI})$ & P.value \\
\hline \multirow{6}{*}{$\begin{array}{l}\text { Rs763780 } \\
\text { IL17F }\end{array}$} & $\mathrm{T} / \mathrm{C}^{*}$ & $5(7 \%)$ & $1(3 \%)$ & (0.26-19.30) 2.23 & 0.415 \\
\hline & $\mathrm{C} / \mathrm{C}$ & $4(6 \%)$ & $2(7 \%)$ & (0.15-4.79) 0.85 & 0.585 \\
\hline & $\mathrm{T} / \mathrm{T}$ & $61(87 \%)$ & $27(90 \%)$ & 0.75 (0.19-2.94) & 0.488 \\
\hline & \multicolumn{5}{|c|}{ Allele frequencies } \\
\hline & $\mathrm{T}$ & $127(91 \%)$ & $55(92 \%)$ & $0.88(0.301-2.61)$ & 0.829 \\
\hline & $\mathrm{C}$ & $13(9 \%)$ & $5(8 \%)$ & $1.12(0.39-3.31)$ & 0.829 \\
\hline
\end{tabular}

*only present significant in TC genotype between two groups.

Table (3): prevalence of IL-17F (Rs763780) gene in patient samples according to sex.

\begin{tabular}{|c|c|c|c|c|c|}
\hline SNP & Genotype & $\begin{array}{l}\text { Male* } n=40 \\
n(\%)\end{array}$ & $\begin{array}{l}\text { Female } \mathbf{n}=\mathbf{3 0} \\
\mathrm{N}(\%)\end{array}$ & OR(95\%CI) & P.value \\
\hline \multirow{6}{*}{$\begin{array}{l}\text { Rs763780 } \\
\text { IL17F }\end{array}$} & $\mathrm{T} / \mathrm{C}^{*}$ & $4(10 \%)$ & $1(3.3 \%)$ & $(0.35-29.36) 3.22$ & 0.281 \\
\hline & $\mathrm{C} / \mathrm{C}^{*}$ & $3(7.5 \%)$ & $1(3.3 \%)$ & $(0.24-22.95) 2.35$ & 0.423 \\
\hline & $\mathrm{T} / \mathrm{T}$ & $33(82.5 \%)$ & $28(93.4 \%)$ & $(0.07-1.71) 0.34$ & 0.164 \\
\hline & \multicolumn{5}{|c|}{ Allele frequencies } \\
\hline & $\mathrm{T}$ & $70(87.5 \%)$ & $57(95 \%)$ & $0.36(0.1-1.4)$ & 0.143 \\
\hline & $\mathrm{C}$ & $10(12.5 \%)$ & $3(5 \%)$ & $2.71(0.71-10.33)$ & 0.143 \\
\hline
\end{tabular}

*only present significant in TC and CC genotype between two genders.

\section{Discussion}

Recently, some studies were improving CD4+ differentiation to Th1 ,Th2 and Th17. Th17 able to producing IL-17 family such as IL-17A and IL-17F and these are playing essential role in autoimmune disorders by stimulation ( acute and chronic ) inflammation such as renal disorders. Also macrophages, mast cells and neutrophils are able to produce IL17A ${ }^{(13)}$.
Renal failure occurs in male more than female and the mean age is $49.5 \pm 5.91$ years respectively, this result agree with ${ }^{(14)}$ this study group consisted of 53 Renal failure patients and present 28 males and 25 females, with a mean of age $51.0 \pm 13.6$ years. Also agree with ${ }^{(15)}$ in this study included 100 sample: males sample was 61 (61\%) and females was 39 (39\%), and age range about $(44.7 \pm 22.1$ year $)$. 
Polymorphisms located for IL-17A and IL-17F within genes coding play a role as genetic factors, and that lead to associate with occurring disease.

In IL17F polymorphisms the genotype $\mathrm{T} / \mathrm{C}(\mathrm{OR}=$ 2.23) show a significant difference between patients and control more than two times. This result similarity with (16) this study show IL-17F frequencies allele A were significantly higher in immune thrombocytopenia for patients and controls : $31.85 \%$ and $18.98 \%$ respectively . Specifically, patients have higher frequencies in AA and AG genotypes compared with controls [AA: $17.12 \%$ vs. 9.49\% and AG: $29.46 \%$ vs. $18.98 \%$ ].

This result is leading to role of $\mathrm{AA}$ and $\mathrm{AG}$ genotypes for IL-17F as risk factors in renal failure disease. IL-17F polymorphism have association with several disease include : IBD (17), Development of asthma (18), autoimmune thyroid diseases (19), acute myeloid leukaemia ${ }^{(20)}$ and recently in MS ${ }^{(21)}$.

Another study is improves the polymorphisms in IL-17A and IL-17F genes play a significant role in Rheumatoid Arthritis (22). In Southern Brazil, (23) were show the relationship between IL17A rs2275913 polymorphisms and chronic periodontitis, while IL17F polymorphism was not associated with same disease. IL-17A and IL-17F play main role in development of inflammation and others act on host defense against infection by prompting gene expression that encoding for several pro-inflammatory cytokines, chemokine and antimicrobial $(24,25)$. IL-17F and IL-17A have same sequence in amino acid ant both have same function. The cytokine have able for activation of neutrophil ${ }^{(26)}$.

\section{Conclusion}

IL-17F play an essential role as pro-inflammatory cytokine in renal failure patients and development disease. And renal failure disease associated with heterozygote allele.

Conflict of Interest:- No there any conflict of the interests that related with this paper.

Source of Funding- self or other source:-

Self-finance.

Ethical Clearance:- Local ethics committee in Diyala University is approve results of our study.

\section{References}

1- Aitken GR, Roderick PJ, Fraser S, Mindell JS, O’Donoghue D, Day J, Moon G. Change in prevalence of chronic kidney disease in England over time: comparison of nationally representative cross-sectional surveys from 2003 to 2010. BMJ open. 2014 Sep 1;4(9):e005480.

2- Akpan EE, Ekrikpo UE. Chronic kidney failure: knowledge of kidney disease, perception of causes and symptomatology in Uyo, Nigeria. Open Journal of Nephrology. 2015 Aug 21;5(03):91.

3- Zhao M, Tan Y, Peng Q, Huang C, Guo Y, Liang G, Zhu B, Huang Y, Liu A, Wang Z, et al. IL6/STAT3 pathway induced deficiency of RFX1 contributes to Th17dependent autoimmune diseases via epigenetic regulation. Nat Commun 2018, 9: 583.

4- Summers, S. A. et al.Endogenous interleukin (IL)-17A promotes pristane-induced systemic autoimmunity and lupus nephritis induced by pristane. Clin. Exp. Immunol.2014, 176, 341-350.

5- Angkasekwinai P, Dong C. T H 17 Cytokines: Characteristics, Regulation, and Biological Function. InTH17 cells in health and disease 2011 (pp. 27-40). Springer, New York, NY.

6- Bagheri M, Omrani D, Abdi-Rad I. Cytokine single nucleotide polymorphisms in Iran. Journal of interferon \& cytokine research. 2006 Jun 1;26(6):414-20.

7- Fonseca PA, Rosse IC, DeMiranda M, Machado MA, Verneque RS, Peixoto MG, Carvalho MR. A new tetra-primer ARMS-PCR for genotyping bovine kappa-casein polymorphisms. Genet Mol Res. 2013 Dec 11;12(4):6521-6.

8- Singh, R., Deb, R., Singh, U., Alex, R., Kumar, S., Chakraborti, S., ... Singh, R. Development of a tetra-primer ARMS PCR-based assay for detection of a novel single-nucleotide polymorphism in the $5^{\prime}$ untranslated region of the bovine ITGB6 receptor gene associated with foot-and-mouth disease susceptibility in cattle. Archives of Virology, 2014 ,159(12), 3385-3389.

9- Sri Manjari, K., Jyothy, A., Shravan Kumar, P., Prabhakar, B., Uma Devi,M., Ramanna, M., et al. A single-nucleotide polymorphism in tumor necrosis factor- $\alpha(-308 \mathrm{G} / \mathrm{A})$ as a biomarker in chronic pancreatitis. Gene.2014, 539, 186-189.

10- You, F., Huo, N., Gu, Y., Luo, M., Ma, Y., Hane, D., Lazo, G., Dvorak, J. and Anderson, O. 
BatchPrimer3: A high throughput web application for PCR and sequencing primer design. BMC Bioinformatics,2008, 9(1), p.253.

11- SAS. 2012. Statistical Analysis System, User's Guide. Statistical. Version 9.1th ed. SAS. Inst. Inc. Cary. N.C. USA.

12- MedCalc,2011. Statistical Software versionn12.1.4.0.

13- Alwahaibi NY, Alissaei HK, Alshihi SA, Alabri N, Albalushi SS, Albalooshi M. Serum levels of TNF- $\alpha$, IL- 6 and IL-10 in haemodialysis and renal transplant patients and in healthy subjects. Portuguese Journal of Nephrology \& Hypertension. 2016 Sep;30(3):194-8.

14- Tabarkiewicz J., Pogoda K., Karczmarczyk A ., Pozarowski P ., Giannopoulos K. The Role of IL-17 and Th17 Lymphocytes in Autoimmune Diseases . Arch. Immunol. Ther. Exp. 2014, 63:435-449 .

15- Saleh MA, Albayati AM. Inflammatory role of some cytokines, immunoglobulins and immunopathogenesis of renal failure complement proteins in a sample of Diyala province patients. BAGHDAD SCIENCE JOURNAL. 2017 Jan 1;14(2):247-53.

16- Liu S, Xiong YZ, Li T, Li Y, Gu SQ, Wang YM, Zhang KH, Hou M, Liu XG. Interleukin-17A and$17 \mathrm{~F}$ gene polymorphisms in Chinese population with chronic immune thrombocytopenia. Annals of Clinical \& Laboratory Science. 2016 May 1;46(3):291-7.

17- Seiderer J, Elben I, Diegelmann J et al .Role of the novel Th17 cytokine IL-17F in inflammatory bowel disease (IBD): upregulated colonic IL$17 \mathrm{~F}$ expression in activated Crohn's disease and analysis of the IL-17F p.His161Arg polymorphism in IBD. Inflamm Bowel Dis. 2008, 14:437-445 .

18- Qian F, Zhang Q, Zhou L, Ma G, Jin G, Huang Q, Yin K. 4 Association Between Polymorphisms in
IL17F and Male Asthma in a Chinese Population. Journal of Investigational Allergology and Clinical Immunology. 2012 Jan 1;22(4):257.

19- Yan N, Yu YL, Yang J et al. Association of interleukin-17A and -17F gene single-nucleotide polymorphisms with autoimmune thyroid diseases. Autoimmunity 2012, 45:533-539.

20- Wrobel T, Ge, bura K, Wysoczan'ska B et al. IL-17F gene polymorphism is associated with susceptibility to acute myeloid leukemia. J Cancer Res Clin Oncol 2014,140:1551-1555.

21- Wang S, Zhai H, Su Y et al. IL-17F but not IL17A gene polymorphism confers risk to multiple sclerosis in a Chinese Han population. J Neurol Sci 2014, 342:133-136.

22- Bogunia-Kubik K, Świerkot J, Malak A, Wysoczańska B, Nowak B, Białowąs K, Gębura K, Korman L, Wiland P. IL-17A, IL-17F and IL23R gene polymorphisms in Polish patients with rheumatoid arthritis. Archivum immunologiae et therapiae experimentalis. 2015 Jun 1;63(3):215221.

23- Zacarias, J., Sippert, E., Tsuneto, P., Visentainer, J., Silva, C. and Sell, A. The Influence of Interleukin17AandIL17FPolymorphisms on Chronic Periodontitis Disease in Brazilian Patients. Hindawi Publishing Corporation Mediators of Inflammation ,2013, Article ID 147056, 8 pages .

24- Dubin PJ, Kolls JK. Interleukin-17A and interleukin-17F: a tale of two cytokines. Immunity. 2009 Jan 16;30(1):9-11.

25- Amarilyo G, Lourenço EV, Shi FD, La Cava A. IL-17 promotes murine lupus. The Journal of Immunology. $2014 \mathrm{Jul}$ 15;193(2):540-3.

26- Xu S. and Cao X."Interleukin-17 and its expanding biological functions," Cellular \& Molecular Immunology,2014, vol. 7, no. 3, pp.164-174 . 